\title{
Males' perspectives on health in Iran: A grounded theory study
}

\author{
Soroor Parvizy ${ }^{1}$, Hamid Peyrovi ${ }^{2}$, Hosein Rostami ${ }^{3}$, Marjan Delkhosh ${ }^{4 *}$ \\ Received: 14 September $2016 \quad$ Published: 24 July 2017
}

\begin{abstract}
Background: Males' health plays a basic role in the community's health, especially in family's health. Health is a multifaceted issue that affects people in all aspects. Health is also one of the 4 metaparadigm concepts in nursing. This study was conducted to explore males' perspectives on health.

Methods: In this qualitative study conducted based on a grounded theory approach, 22 males were selected through a purposive sampling. Data were collected through semi-structured interviews and continued until data saturation. Data analysis was done using Strauss and Corbin's three-stage coding process.

Results: Based on the perspectives of the participants, 8 categories emerged, which are as follow: psychological health; physical health; family health; spiritual health; welfare and social health; health and relationships; sexual health; and occupational-economic health. Psychological health was emerged as the core variable.

Conclusion: As a multifaceted phenomenon, health is an individual's general condition in all these aspects, particularly psychological aspect. Males' health should be taken into account for the role they play in managing the family. Males as the family heads require evidence-based decision making and planning.
\end{abstract}

Keywords: Health, Male, Family, Qualitative Research, Grounded Theory

Copyright $\odot$ Iran University of Medical Sciences

Cite this article as: Parvizy S, Peyrovi H, Rostami H, Delkhosh M. Males' perspectives on health in Iran: A grounded theory study. Med J Islam Repub Iran. 2017 (24 July);31:40. https://doi.org/10.14196/mjiri.31.40

\section{Introduction}

Health means a general, physical, and mental condition in which the individual is free from illness, injury, or pain (1). World Health Organization (WHO) defines health as "a state of complete physical, mental, and social wellbeing, and not merely the absence of disease or infirmity" (2).

Gender is one of the most important social and cultural factors influencing health (3) and its related behaviors. Moreover, gender is also one of the most important determinants of disease. The role of gender in the pattern of disease and its prevention has been demonstrated by many studies (4-8). Despite the vast improvements in the field of public health and complex therapeutic approaches, males are less heal thier than females and are more likely to suffer from disability, physical illnesses, and physical injuries $(3,9,10)$. Males constitute $50.6 \%$ of the world's population, and their health is affected by physiological, spiritual, social, cultural, and biological factors (11). Also, in Iran, males account for $51 \%$ of the population and their life expectancy is 71.7 years (12).

Males suffer more from serious illnesses, are less attentive to their diseases (13), and more likely to die in younger ages than females (11). Moreover, being exposed to stressful environments, the physical and social envi-
Corresponding author: Marjan Delkhosh, mdelkhosh@razi.tums.ac.ir

1. Department of Pediatric Nursing, Faculty of Nursing and Midwifery, Iran University of Medical Sciences, Tehran, Iran.

2. Nursing Care Research Center, Iran University of Medical Sciences, Tehran, Iran.

3. Health Research Center, Baqiyatallah University of Medical Sciences, Tehran, Iran.

4. School of Public Health, Tehran University of Medical Sciences, Tehran, Iran. $\uparrow$ What is "already known" in this topic:

Gender is one of the most important social and cultural factors influencing health and its related behaviors. The role of gender in the pattern of disease and its prevention has been demonstrated. Males' health should be taken into account for the basic role they play in managing the family and community's health.

\section{$\rightarrow$ What this article adds:}

Based on the males' perspectives on health in Iran, 8 main categories emerged as follow: psychological health; physical health; family health; spiritual health; welfare and social health; health and relationships; sexual health; and occupational-economic health. As a multifaceted phenomenon, health is the male's general condition in all these aspects, particularly psychological aspect. 
ronmental risks, occupational hazards, relationship with their superior in the workplace, job security, and ethical and racial dicrimination are the factors influencing males' psychological health(14). On the other hand, in most parts of the world, death rates are higher among males than females (15). Thus, it can be stated that males have less knowledge about their health or seek health services less than females, and thus they are more likely to encounter health threatening risks (11). Studies conducted on the Iranian society also indicated that Iranian males are more likely to be inflicted by diseases compared to females (16).

Health is one of the 4 metaparadigm concepts of nursing along with the environment, patient, and the nurse (17). Basically, health promotion is one of the most important responsibilities of nurses, which encompasses most of their tasks (18). Understanding the relationship between what the researchers have identified as the main issues of health and individuals' main concern about health is useful for those nurses who intend to work in the field of health and primary health care (19). Therefore, familiarity with different perspectives on health and conditions related to health can increase the success of nueses in providing an effective nursing care (20).

Recently, a qualitative research was conducted by Ramezani Tehrani to identify the perceptional barriers for health among males. They found that the main concern of most males was something other than their health issues. A few number of males considered health as an important issue because they were afraid of the negative effects of their illness (due to the lack of attention to health) on their family members and losing their ability to perform social activities. According to the findings of that research, the economic, sociocultural, and family issues, lack of social security, the weakness of macromanagement and bioenvironmental factors were the main health barriers that prevented males to consider health as a priority(21).

Some qualitative studies have also indicated that males provide a certain definition of health and its related factors (22). Kalvente's research (2012) demonstrated that males tended to overrate their health, hiding their problems behind the 'tough guy' stereotype associated with masculinity. These factors can significantly affect males' attitude towards health and its priority in their lives; and as a result, influence their lifestyle and coping with illness (23).

Thus, given the importance of males' health, this study was conducted to explore their perspectives on health.

\section{Methods}

This qualitative study was conducted based on a grounded theory approach. The participants in this study were 22 males aged 20 to 50 years, who were willing to participate in interviews (Volunteer Sampling), and were not addicted or suffering from acute or chronic diseases according to their self-report. The participants were selected through purposeful sampling, moreover, considering the maximum variation of the data, sampling continued until data saturation. To collect data, in-depth semistructured individual interviews and interactive interviews were conducted using the interview guide. Some of the questions asked were as follow: What comes to mind when you hear the word 'health'?, and "What does a male's health mean and how is it achieved?" Then, according to the participants' responses, the interviews continued. To analyze the data, 3 stages of open coding, axial coding, and selective coding were done. In all these stages, constant comparative analysis was used. To ensure the trustworthiness of data, some measures were taken including persistent observation, prolonged engagement, good communication with the participants, triangulation of time, and checking codes and categories through peer check (External Check) and double check by the participants as the member check (Member Check) $(24,25)$.

Credibility was established through member check (10 transcripts were revised by 4 participants.). The missed codes were added and new codes were replaced after few given comments and peer check (by research team and experts in qualitative researches). For the member check, 4 participants were contacted after analysis and asked to confirm the process, and the main and subcategories. Moreover, peer check was performed to establish intertranscript reliability by a number of colleagues and the research team members. The results were also checked with the males who did not participate in this research. The maximum variation of sampling has been used to enhance the confirmability and credibility of data. Also, the participants were selected from a variety of different academic levels, academic performance, and social class. Good communication skills with participants along with providing a comfortable and cozy place to conduct the interviews helped achieve rich and deep data.

Obtaining written informed consent, maintaining privacy and confidentiality of participants' information, and the right to withdraw from the study at any time were taken into account as the ethical consideration of this research. This study was conducted in the form of a research project. The ethics committee of Iran University of Medical Sciences approved this research protocol (Code: 953).

\section{Results}

In this study, 22 males aged 20 to 50 years, who were healthy according to their self-report, and were willing to share their perspectives on the issue of health participated in this research. Most males, who participated in this study $(50 \%)$, aged 20 to 30 years of whom $45 \%(n=10)$ had a diploma, 64\% $(n=14)$ were married, and 50\% $(n=11)$ self-employed. In the beginning, 560 codes were obtained, which were organized into 8 main categories. Also, in this study, psychological health was recognized as the core variable. During the axial coding stage, 8 main categories emerged, which are as follow:

1. Psychological Health: Psychological aspect was the most important aspect of health in this study. One participant stated, "When it is said that someone is healthy, in my opinion, it refers to psychological health because one may be healthy or have a strong body, but be mentally ill. Psychological health is more important than physical health." Code 3.

In addition, according to our participants, having mental 
comfort was a basis for other aspects of health, and in contrast, stress was known as one of the confounding elements of males' health.

2. Physical Health: According to the participants' viewpoints, physical health plays an important role in males' health. The males were less caring about their health status due to being too busy, inattentive, and feeling strong and masculine. Some participants believed that paying too much attention to health is considered a feminine and delicate behavior. For the males, health was as important as a capital to start a business. One participant said, "Health is something like the capital of the body; the capital of human, if there is no health, everything will be impractical." Code 10.

Most previous health experiences were related to physical health, healthy diet, exercising, and being strong, and minimum health was related to pain, weakness, illness, and physical disability. The participants also pointed out to insufficient rest and loss of physical strength along with aging as the other factors that could negatively influence their health.

3. Family Health: For the participants, their families, especially their wives, were both the reason for being healthy and being unhealthy. Males' comfort was always the reflection of the family's health, affection in the family, proper relations in the family, being respected by women, and the community. In this regard, one of the participants stated, "I almost always see that if a man has got any emotional problems with his wife or children, he will get mentally ill. He may take sedative drugs, visit a doctor, and even suffer from physical illnesses." Code 3.

On the other hand, the beginning of the paternal role and its continuation played a significant role in creating and maintaining a sense of well-being in males. Also, the males participating in the study mentioned that lack of free time, being too busy for a small child, and constraints after family formation were the factors decreasing their fun and happiness after marriage .In contrast, single males envied their peers who were married and had children. However, the males believed that the birth of a child, and consequently the emotional distance between the couples, focusing on the child's needs rather than their own needs, fading respect, and children's emotional relationships with their fathers due to the generation gap, and the rising expectations of children could all reduce the level of males' health.

4. Spiritual Health: For most males, religious experience was considered the experience of health because of the sense of relaxation and solitude experienced along with the religious rituals. The role of praying is clear in this quotation: "Whenever I attend a praying ceremony, I feel relaxed and free and rarely become angry; praying is very important; I can do my tasks better after praying; religious practices are very effective." Code 1 .

Also, the participants considered religious beliefs, trust in God, and not eating unlawful (haram) food as the aspects of health. Earning legitimate (Halal) income was emphasized by almost all the participants. From the participants' point of view, the unhealthiest males were those who had not a legitimate income.
5. Having Welfare and Social Health: From the males' point of view, having social welfare was one of the most important aspects of health, and especially a symbol for males' authority. The participants considered welfare, balance, and predictable social situation as the factors contributing to males' health. Some participants believed that socioeconomic problems could cause the uncomfortable feeling of life for them. Welfare and social security were sometimes males' desire.

Also, having insurance, the existence of facilities and investment opportunities for the youths, the possibility to continue their education, having an appropriate social circumstance, having no discrimination in the society, obeying the law, having proper social relations, controlling and decreasing corruption and delinquency in the community, controlling drug abuse, and problems of urbanization in the community were identified as the determinants of males' health.

6. Health and Relationships: According to the participants, relations affected males' health both in the family and the work place. One participant stated, "When a man arrives at his work in the morning and sees his colleague and talks to him, he may forget his problems or feel better if he is depressed or has got any problems." Code 5.

On the other hand, the participants believed that due to the generation gap, they were less successful in transferring information to the new generation. Failure in relations, the lack of healthy relationships, and lack of empathy were also the factors influencing males' health. The males also mentioned the important role of media, awareness and education (particularly health education), informing about addiction, and moral issues.

7. Sexual Health: With regards to the useful information about marital relationship, the participants emphasized the importance of knowledge of sexual health, establishing training centers, and providing sex education and believed that having a safe sex and the existence of facilities for marriage or controlled sexual relations are necessary for males' health. With regards to the lack of premarital counseling services, one of the participants said, "Before marriage, if a man receives training about health problems, it will be very beneficial... We don't know anything about these issues, our parents did not share information on sexual issues openly and we don't have any experiences or skills." Code 5.

8. Occupational and Economic Health: The meaning of health was entirely manly from the males' perspective and was linked to the terms like strength, property, and capital. The financial affordability of the family was also considered as one of the meanings of health for males. In the males' viewpoints, job satisfaction, education-based employment, progress, having good and healthy communication at the workplace, and having a job appropriate to the individual spirit were important factors affecting their career health. However, lack of job security, fear of getting fired, inappropriate workplace, and difficult job were the threatening factors of males' health.

Moreover, lack of a sense of well-being was more common among males, especially those who had more economic problems. One participant said, "Males are 


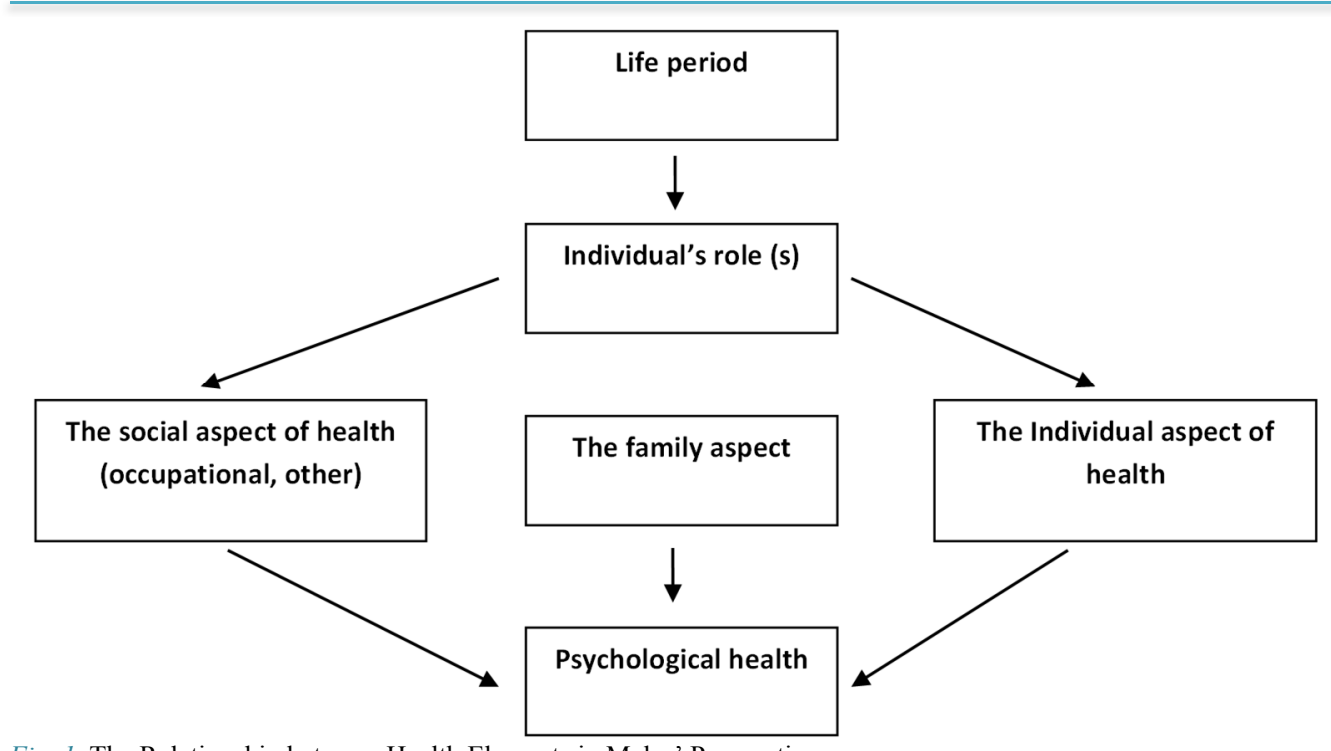

Fig. 1. The Relationship between Health Elements in Males' Perspectives

tired of the condition in which they have to get up every morning, go to work and fight for life, then come back home at night without earning anything; this is humiliating for males." Code 3.

\section{Selecting the Core Variable: Psychological Health}

In the third stage of the study, using selective coding, we aimed at discovering the core category. Accordingly, out of the 8 variables selected as the abstract categories, psychological health was finally recognized as the core variable. According to the findings, psychological health has been the reflection and result of males' health. Males achieve psychological health through the following: physical health, family health, spiritual health, having social health and welfare, healthy relationships, occupational and sexual health (Fig. 1).

Finally, in response to the question that what the concept of health from the perspectives of male is, it was found that health is a multidimensional phenomenon from the males' points of view. Health is the outcome of taking into accounts all these aspects. However, the role of each of these aspects in various periods of life (youth, adulthood, etc.) is different, and therefore to protect and promote health in different periods of life, the importance of each of these aspects should be considered in that particular period.

The dimension or dimensions, which should be considered more during a particular period in the life of a male, depend on his role in that period of life. In other words, the individual's role in a particular time in life can determine the health aspects priorities and can, consequently, determine which aspect should be given more attention on that certain period.

\section{Discussion}

The World Health Organization (WHO) defines health as "a state of complete physical, mental, and social wellbeing, and not merely the absence of disease and infirmi- ty. The participants in the present study understood health as a set of physical health, psychological health, spiritual health, family health, occupational health, sexual health, welfare, and social health. In addition, they emphasized the role of media, education, and communication in promoting the health status.

Mental health is a state of well-being in which individuals can realize their own potentials, cope with the normal stresses of life, work productively and fruitfully, and contribute to their community (26). As Barry states, mental health is essential to good health and quality of life and contributes to the functioning of individuals, families, communities, and societies $(26,27)$. Scott et al. have also considered mental health as an inseparable component of the policies and programs related to the population health. In their study, the risk of disability in people with mental disorders was higher than those with physical conditions $(27,28)$. In the present study, the participants also considered psychological health as one of the important aspects of health.

The participants also believed that the level of males' health has dropped in the community following a decline in health after the age of 40, the increase of depression among the middle class males, and the increase of psychological distress. Moreover, Evans et al. found that the middle-aged males often silently suffer from depression. They may experience symptoms of depression without acknowledging being depressed and are not able to recognize mental health problems, and this can lead to the higher rates of suicide among the male population $(28,29)$.

Young argues that stressful situations, social, physical, job hazards, and racial discrimination are the effective factors on males' psychological health (14). Consistent with his findings, the participants of this study found that psychological, social, economic, and job stresses influenced their health.

Physical health was another dimension of health mentioned by the study participants. According to our finding, males were highly negligent of their health. Other studies 
have also indicated that males are less likely to seek social support than females because health promoting behaviors are related to femininity and risk-taking behaviors are related to masculinity. Given that illness is associated with weakness and vulnerability, males are reluctant to seek treatment because of the masculine behaviors or avoidance of femininity (29). When a man declares honorably, "I didn't go to a doctor last year", he actually describes his health functioning and presents his masculinity (30). These cases will increase the task burden of public education of the media, raise the number of masculine groups for health, and increase the responsibility of the nurses in training and screening males, especially in factories and masculine workplaces.

Family health was another aspect of health pointed out by the study participants. Although from the males' viewpoints, marriage and family formation as well as having a wife and children were difficult, they believed that marriage has improved their health and they considered their families as their best friends. In accordance with our results, in the study of Zhu et al. carried out to determine the effect of being married on the health and survival of elderly Chinese males, it was revealed that being married, good quality of life, and duration of marriage influenced the health and survival of males $(30,31)$. Moreover, our participants believed that infidelity, divorce, or death of the spouse were factors that could adversely affect their health. Also, many studies showed that depressive symptoms are related to the current marital status, and married individuals report lower depressive symptomatology (32).

Another dimension of health mentioned in this study was sexual health. WHO has defined sexual health as a state of physical, emotional, psychological, and social well-being related to sexuality $(33,34)$. Moreover, the participants of the present study also signified the role of sexual issues on health, and emphasized the importance of a healthy relationship with the opposite sex and religious consideration (religious rulings) in sexual issues as well as the importance of sex education and the need for counseling services to promote males' health.

Having occupational health and favorable economic conditions were other aspects of health mentioned by the participants. In this study, employment was considered as the basis for males' health because the economic aspect was one of the most important aspects of a man's life and income was a prerequisite for paying life expenses.

In Tajvar's study, economic situation was one of the most important predictors of physical and psychological health-related quality of life (35). On the other hand, the males participated in our study mentioned that work pressure and workload was the most important factors influencing their health. Also, in other studies, the relationship between stress and health had well been confirmed and stress [occupational] found to have a major impact on males' health (31).

One of the other aspects of health highlighted by the males was spiritual health. In various studies, the influence of spirituality and religion on health has been demonstrated. Results of a study by Michael (2009) reported that males obtain more mental health benefits from religious involvement compared to females $(27,33)$. In the present study, the males considered spiritual health as one of the effective factors on their health and believed that distancing from religion and forgetting God lead to the sense of loneliness and decreased level of health.

Unlike our findings, Vaillant et al. in their study found no correlation between religious involvement with physical, mental, and social health of males in late life, but found that religious involvement had the most mental health benefits on those who had the fewest human and social resources (36).

Another dimension of health mentioned in this study was social welfare. According to the participants, lack of planning for free time and sometimes the low vitality of the environment were the factors leading to a decline in their health. The availability of illicit drugs in cities and its relevant problems were the most important concerns noted by the participants. On the other hand, they considered education and insurance as the effective factors improving males' health. In a study on the quality of life by Tajvar et al. they found that people with lower education had lower life quality (35).

The participants pointed out to the importance of communication and emphasized the necessity of developing and maintaining a relationship with people and receiving information. In this study, the participants highlighted the important role of media in promoting culture, education (especially health education), warning about addiction, and moral issues.

Given the qualitative approach of this study, one of the limitations of the study was its dependence on the circumstances (especially time), while it may be considered as the strength of the study from a different view considering the environmental and cultural variables. We recommend that a phenomenological study be conducted to explore the experience of the family and males' health and identify the risk factors for the family and male's health. In addition, designing and implementing action research is highly recommended to empower and create health behaviors and reduce the risk factors for males' health. Moreover, conducting the grounded theory studies to explore males' marital satisfaction process is recommended.

\section{Conclusion}

Considering the role of males in the family and society, it is important to pay more attention to their health. The following efforts are essential to maintain males' health: focusing on the males' health, providing necessary education for a healthy lifestyle, stress management, coping skills, and financial management of the family.

Providing screening tests and training on sexual health before puberty and during adolescence and youths through schools, health centers, universities, and the media can help males to resolve many of their physical, emotional, mental, and family issues.

On the other hand, the relevant governmental agencies should focus on providing appropriate employment conditions, economic justice and social welfare to reduce unemployment level, poverty, and social problems and promote males' health. 


\section{Acknowledgements}

This study was approved and funded by the Research Committee of Iran University of Medical Sciences (Grant No. 1388/12/953). We gratefully acknowledge the participants who participated in the interviews.

\section{Conflict of Interests}

The authors declare that they have no competing interests.

\section{References}

1. Organization WH. Constitution of the World Health

Organization - Basic Document. 45th edition ed2006 October 2006.

2. Sadana R, Petrakova A. Shaping public health education around the world to address health challenges in the coming decades. Bull World Health Org. 2007;85(12):902-3

3. Strandberg AY, Strandberg TE, Pitkälä K, Salomaa VV, Tilvis RS, Miettinen TA. The effect of smoking in midlife on health-related quality of life in old age: a 26-year prospective study. Arch Intern Med. 2008;168(18):1968-74.

4. Abad-Díez JM, Calderón-Larrañaga A, Poncel-Falcó A, PobladorPlou B, Calderón-Meza JM, Sicras-Mainar A, et al. Age and gender differences in the prevalence and patterns of multimorbidity in the older population. BMC Geriatr. 2014;14(1):1.

5. Biplab D, Mutharayappa R. Gender differential in disease burder: Its role to explain gender differential in mortality. 2009.

6. Najafi M, Sheikhvatan M. Gender differences in coronary artery disease: correlational study on dietary pattern and known cardiovascular risk factors. Int J Cardiovasc Res. 2013;7(4):124.

7. Shaw LJ, Shaw RE, Merz CN, Brindis RG, Klein LW, Nallamothu B, et al. Impact of ethnicity and gender differences on angiographic coronary artery disease prevalence and in-hospital mortality in the American College of Cardiology-National Cardiovascular Data Registry. Circulation. 2008;117(14):1787-801

8. Vlassoff C. Gender differences in determinants and consequences of health and illness. Journal of Health, Population and Nutrition. 2007:47-61.

9. Galdas PM, Cheater F, Marshall P. Men and health help-seeking behaviour: literature review. J Adv Nurs. 2005;49(6):616-23.

10. O'Brien R, Hart GJ, Hunt K. " Standing out from the herd": Men renegotiating masculinity in relation to their experience of illness. International Journal of Men's Health. 2007;6(3):178.

11. Wilkins D. Men's health around the world: a review of policy and progress across 11 countries: 178. Journal of Men's Health. 2009;6(3):272-.

12. Khosravi A, Najafi F, Rahbar M, Atefi A, Motlagh E, Kabir M. Health indicators in the Islamic Republic of Iran Broadcasting. Kermanshah: Health Research Center, Kermanshah University of Medical Sciences and Health Services; 2010.

13. Näslindh-Ylispangar A. Men's health behaviour, health beliefs and need for health counselling: A study amongst 40-year-old males from one Helsinki City region. Academic Dissertation. 2008.

14. Young A, Conrad D, White A. Urban distress and the mental health of men. Promoting Men's Mental Health Radcliffe Publishing, Oxford. 2010:39-56.

15. Tong SF, Low WY, Ismail SB, Trevena L, Willcock S. Malaysian primary care doctors' views on men's health: an unresolved jigsaw puzzle. BMC Fam Pract. 2011;12(1):1.

16. Meleis AI. Theoretical nursing: Development and progress: Lippincott Williams \& Wilkins; 2011.

17. Jarrin OF. The integrality of situated caring in nursing and the environment. ANS Advances in nursing science. 2012;35(1):14.

18. Laws T. A handbook of men;s health: Elsevier Health Sciences; 2006.

19. Kozier B. Fundamentals of nursing: concepts, process and practice: Pearson Education; 2008.

20. Ravenell JE, Johnson Jr WE, Whitaker EE. African-American Men's perceptions of health: a focus group study. J Natl Med Assoc. 2006;98(4):544.

21. Ramezani TF, Amiri P, Simbar M, Rostami DM, Azizi F. Do Men Consider Health as a Priority? A Qualitative Study. 2011.
22. del Mar García-Calvente M, Hidalgo-Ruzzante N, del Río-Lozano M, Marcos-Marcos J, Martínez-Morante E, Maroto-Navarro G, et al. Exhausted women, tough men: a qualitative study on gender differences in health, vulnerability and coping with illness in Spain. Sociol Health Illn. 2012;34(6):911-26.

23. Graneheim UH, Lundman B. Qualitative content analysis in nursing research: concepts, procedures and measures to achieve trustworthiness. Nurse education today. 2004;24(2):105-12.

24. Speziale HS, Streubert HJ, Carpenter DR. Qualitative research in nursing: Advancing the humanistic imperative: Lippincott Williams \& Wilkins; 2011.

25. Corbin J, Strauss A. Basics of qualitative research: Techniques and procedures for developing grounded theory: Sage publications; 2014.

26. Barry MM. Addressing the determinants of positive mental health: concepts, evidence and practice. Int $\mathrm{J}$ Ment Health Promot. 2009;11(3):4-17.

27. Scott K, Von Korff M, Alonso J, Angermeyer M, Bromet E, Fayyad $\mathrm{J}$, et al. Mental-physical co-morbidity and its relationship with disability: results from the World Mental Health Surveys. Psychol Med. 2009;39(01):33-43.

28. Evans J, Frank B, Oliffe JL, Gregory D. Health, illness, men and masculinities (HIMM): a theoretical framework for understanding men and their health. Journal of Men's Health. 2011;8(1):7-15.

29. Broom A, Tovey P. Men's health: Body, identity and social context: John Wiley \& Sons; 2009.

30. Zhu H, Gu D. The protective effect of marriage on health and survival: Does it persist at oldest-old ages? J Popul Ageing. 2010;3(34):161-82.

31. Paul KI, Moser K. Unemployment impairs mental health: Metaanalyses. J Vocat Behav. 2009;74(3):264-82.

32. Cacioppo JT, Hughes ME, Waite LJ, Hawkley LC, Thisted RA. Loneliness as a specific risk factor for depressive symptoms: crosssectional and longitudinal analyses. Psychol Aging. 2006;21(1):140.

33. McFarland MJ. Religion and mental health among older adults: Do the effects of religious involvement vary by gender? The Journals of Gerontology Series B: Psychol Sci Soc Sci. 2009:gbp112.

34. Health WHOR. Medical eligibility criteria for contraceptive use: World Health Organization; 2010.

35. Tajvar M, Arab M, Montazeri A. Determinants of health-related quality of life in elderly in Tehran, Iran. BMC Pub Health. 2008;8(1):1.

36. Vaillant G, Templeton J, Ardelt M, Meyer SE. The natural history of male mental health: Health and religious involvement. Soc Sci Med. 2008;66(2):221-31. 